\title{
Environmental and social impact free stance and consequences on the operational performance
}

\begin{abstract}
The luxury fashion industry, which used to be geographically centralized, sought growth opportunities to expand global sales. Luxury fashion businesses have significantly grown, have created a depiction of glamor and exclusiveness, and thus this global phenomenon has reached highly lucrative financial figures. Yet, this global expansion has brought noteworthy challenges including the execution of vertically integrated supply chains (SCs). Relatedly, SC complexity, rapidly changing market dynamics and growing concerns in terms of the footprint generated by global fashion operations left many people wonder: what do luxury fashion companies really do to truly embark on not only financial but also environmental as well as social sustainability? The myth of sustainability in fashion operations has been receiving attention; nevertheless the real focus must be switched from company boundaries to supply networks considering that fashion companies are held responsible for social and environmental records of their upstream suppliers. In this vein, it is vital to examine to what extent sustainability management is integrated and which capabilities are developed and deployed along upstream SCs. Using a case study method with seven upstream suppliers, including both direct and indirect suppliers of two massive luxury fashion companies, sustainability management capabilities were represented in two clusters; namely practical and interactive. It was found that the deployment of such SMCs could be positively and directly associated with performance outcomes. An integrated framework encompassing the components of capability development, sustainability practices, buyer-supplier-supplier relationship execution, and performance outcomes suggests that taking an environmental and social impact free stance could improve some operational results.
\end{abstract}

Keywords: sustainable supply chain management, luxury fashion industry, dynamic capabilities, social issues, environmental issues, regulatory compliance, textile and clothing agreement, cross-functional integration, external stakeholder, research methodology, dynamic capabilities, positioning stakeholder theory, logistics social responsibility
Volume I Issue 4 - 2017

\author{
Hakan Karaosman, ' Alessandro Brun,' \\ Gustavo Morales Alonso ${ }^{2}$ \\ 'Department of Management, Polytechnic University of Milan, \\ Italy \\ ${ }^{2}$ Department of Industrial Management, Technical University of \\ Madrid, Spain
}
Correspondence: Hakan Karaosman, Department of Management, Economics \& Industrial Engineering, Polytechnic University of Milan, 20156 Milan, Italy,
Email Hakan.karaosman@polimi.it

Received: October 01, 2016 | Published: April 20, 2017
Abbreviations: SC, supply chain; SSCM, sustainable supply chain management; SMCs, sustainability management capabilities; RBV, resource-based view; EMCs, environmental management capabilities; SEV, sustainable evaluation and verification; OM, operations management

\section{Introduction}

Fashion industry is a global force. Luxury fashion, on the other hand, has always been relevant since it represents exclusivity, glamour and distinction. Luxury fashion operations were used to be coordinated in local settings the story has drastically changed. During the SC revolution of the 1990s, individual enterprises became members of larger networks that evolved from independent units to integrated SCs. ${ }^{1}$ Further, following the cancellation of the quotas in 2005 as a part of the Textile and Clothing agreement, ${ }^{2}$ the fashion industry has gone global and has become the world's third biggest industrial industry following automotive and electronics manufacturing, ${ }^{3}$ Nevertheless, in this highly global context, supply networks exceed the boundaries of a single company ${ }^{4}$ and reach an interlinked and interrelated net where multi-tier suppliers are positioned.

Conversely, the need to integrate environmental and social sustainability into operations management emerges as a pivotal topic as a consequence of the on-going exploitation of renewable and nonrenewable resources. For example, production of one $\mathrm{kg}$ of cotton requires almost 20.000 litres of water, ${ }^{5}$ additionally, approximately 8.000 synthetic chemicals are utilized while turning raw materials into textile. ${ }^{6}$ Similarly, manufacturing phase generates a significant amount of footprint, including fabric waste, e.g. almost 20 percent of the fabric swept off the floor of cutting room, ${ }^{7}$ and water use, e.g. 200 tons of water is needed per ton of fabric ${ }^{8}$ In this vein, the anticipated consumption for an annual global production of 60 million tonnes of fabrics require 1 trillion kilowatt hours of electricity. ${ }^{9}$

On the social axe of sustainability, there appears to be a conflict between growing commercial pressures and social responsibility. ${ }^{10}$ Hidden subcontractors,${ }^{11}$ occupational health and safety violation, ${ }^{12}$ issues surrounding workers' right, ${ }^{13}$ and child labour in fashion $\mathrm{SCs}^{14}$ are only some of the most critical issues making the headlines. Therefore, global fashion retailers are vilified for the length of their SCs and the behaviour of their overseas subcontractors. For example Victoria's Secret was criticized for child labour usage for cotton picking in Burkina Faso, ${ }^{15}$ similarly Mulberry slammed for worker exploitation after Turkish factory. ${ }^{13}$ These critical examples justify that the most critical issues occur at the upstream level. ${ }^{16}$ 
All in all, although an increasing amount of environmental risk could be found at the buying firms' $\mathrm{SCs},{ }^{17}$ the problem does not only constitute internal activities but also those of upstream suppliers. Cross-functional integration within a company and integration with upstream suppliers on implementing environmental management practices is required. ${ }^{18}$ Nonetheless, many upstream suppliers encounter difficulties meeting the environmental and social standards of the buying firms due to limited financial funds, lack of human resource expertise and acting on relevant information. ${ }^{17}$ Linking sustainable behaviours and developing dynamic capabilities with suppliers could provide an impetus for sustainability integration. However, the role of upstream suppliers has received less attention in prior research despite a growing body of research on sustainable supply chain management (SSCM) ${ }^{19}$ A remarkable progress has been made in the buyer-supplier relationship studies over the past decades. Further, despite some notable exceptions of green SCM..$^{20,21,18}$ the development of SSCM literature has rather focused on a single entity than looking at the entire chain. ${ }^{22}$ Previous studies called for more empirical studies to develop a better understanding of the capabilities of the first and second level suppliers.

Furthermore, SCM literature mostly neglected the social aspects of sustainability. There are important studies, including social responsibility and consumer trust, ${ }^{23}$ sustainability reporting, ${ }^{24}$ sustainable supply management, ${ }^{25}$ and supplier selection problems. ${ }^{26}$ Yet, the majority of these studies examined sustainability activities as separated constitute. With respect to the consequences of sustainability management on the performance, previous studies address that environmental management practices lead to a positive performance on a plant's quality, delivery, flexibility and cost performance. ${ }^{27}$ The measurement and management of sustainability performance of SCs could lead towards a more radical change in management thinking to secure competitive advantage. ${ }^{28}$ Furthermore, sustainability practices are related to the issues of the quality of the relationships inside the chain and the relationships to external stakeholders. Thus, sustainability practices could result in more comprehensive sustainability performance measurement systems, and a stronger positioning toward the stakeholders. ${ }^{29}$ Nevertheless, some other studies stress that a positive empirical relationship between sustainability management and company performance does not necessarily exist., ${ }^{30}$ for example, argue that internal social sustainability programmes improve environmental and social performance but they could also increase manufacturing costs in the short-term. Furthermore, ${ }^{31}$ argue that green SCM do not directly affect economic performance, rather do it indirectly.

Prior studies stress that an empirical investigation is needed to justify the impact of sustainability on operational and organizational performance. Therefore, the previous concerns of SCM need to be expanded to incorporate social and environmental considerations with economical indicators, especially in global SCs. Given this gap; this study integrates a sustainability management approach to elaborate a model linking dynamic sustainability management capabilities (SMCs) with operational and organizational performance. The model examines how practical and interactive capabilities developed to improve environmental and social sustainability performance could impact organizational and operational performance. The model specifies variables to take an environmental and social impact free stance, and suggests that these practical and interactive capabilities directly and positively affect organizational and operational performance outcomes. Taking a focused stance, this study was built by considering social and environmental issues, by incorporating dynamic capabilities, and by linking them to the performance. Thus, previous research on SSCM that often considered the impact of SCs on environmental performance is extended. To this end, case studies of seven upstream suppliers, encompassing both direct and indirect suppliers of two massive global luxury retailers were used to build a testable model of the practices, dynamic capabilities and performance outcomes. To this end, we explore three questions: First, which are the significant drivers for suppliers to develop and deploy SMCs? Second, which are the components to conceptualize an integrated model for sustainability management at upstream levels? Lastly, which are the consequences of SMCs on operational and organizational performance? The paper is developed as follows: Section 2 addresses the theoretical foundation, under which SCM (2.1), dynamic capabilities (2.2) and the impact on performance (2.4) is in detail discussed. Section 3 delivers the research methodology followed by results and findings in Section 4. Discussion and research propositions are addressed in Section 5 before Section 6 provides the final conclusions.

\section{Theoretical foundations}

\section{Conceptualizing supply chain management and sus- tainability}

Companies have redefined the concept of operations management using supply chain (SC) perspective through the incorporation of upstream and downstream partners into the boundary of investigation and management. Sustainable SCM (SSCM) is essentially an extension of green SCM, and it emphasizes the environmental and ethical aspects of sustainability in the supply chain. ${ }^{32}$ In this respect, SSCM could be defined as the management of material, information and capital flows as well as cooperation among companies throughout SCs while considering goals from all three dimensions of sustainable development, i.e., economic, environ-mental and social. ${ }^{33}$

Sustainability in SCM has captured the interest and vision of academics since the early 1990s. Earlier research has dealt with several environmental and social issues, including sustainable apparel product development, ${ }^{34}$ sustainable fashion SCs,${ }^{35}$ reverse logistics, ${ }^{36}$ logistics social responsibility, ${ }^{37}$ carbon accounting, ${ }^{38}$ the case of fair trade products, ${ }^{23}$ positioning stakeholder theory within the debate on $\mathrm{CSR},{ }^{39}$ social and environmental reporting, ${ }^{40,41}$ sustainable purchasing and supply ${ }^{42}$ environmental impacts of production and consumption in country specific contexts, ${ }^{2}$ governance of sustainable SCs in the fast fashion industry, ${ }^{43} \mathrm{CSR}$ in garment sourcing networks, ${ }^{10}$ multi tier sustainable $\mathrm{SCs},{ }^{16}$ and sustainability integration into global fashion operations. ${ }^{44}$ Nonetheless, there is a further need in research to address the specific relationship between companies' internal and external sustainability strategies, and the influence of capabilities developed for sustainability management on operational performance areas. In this vein, SSCM requires a judicial combination of company resources, organizational capabilities as well as a fit between sustainability and operational outcomes.

Towards sustainability in luxury fashion SCs: The personal luxury goods ballooned to more than $250 €$ billion in $2015 .{ }^{45}$ Nevertheless, despite the growth and high profit margins, the global fashion market is affected by macroeconomic, socio-political and natural events. Thus, excellence in today's luxury must be pursued along the SCs in product line management, service management and channel management simultaneously. ${ }^{46}$ Nevertheless, as previously stressed; growingly 
scarce natural resources and rising commodity prices create critical variables for luxury fashion companies to remain profitable. With today's global economic uncertainty, globalization and growing SC complexity, a renewed focus to sustainability is required. $\mathrm{As}^{47}$ suggest fashion SCs and its main foundations must be revised, and extended by taking such essential considerations as ethical aspects, social sustainability, and full cycle of corporate reporting. Hence, the core business of each company should become a part of the core business of the entire SC by going beyond the boundaries of a single company. This shows the relevance of a further investigation to suggest how to take an environmental and social friendly stance that could influence operational and organizational outcomes.

The strategic importance of upstream suppliers for sustainability: Embedding social and environmental management into SCM is needed yet challenging. SMC development could be demanding, as competitive pressures of cost, quality, and unpredictability of market demand and product variety escalate. The analysis of ${ }^{48}$ articulate that the nature of stakeholder exposure defines how social and environmental capabilities impact social and environmental outcomes. Luxury fashion companies are exposed to scrutiny to advance their sustainability performance in the context of social and environmental behaviours and their purchasing power and technical capabilities are critical to diffuse the sustainable behaviour throughout the chain. $\mathrm{As}^{16}$ state the most critical environmental and social issues in SCs are generated by suppliers located in the second tier or further upstream. However, as mentioned, many small and medium sized suppliers encounter challenges in responding to environmental pressures due to limited capabilities and available resources, ${ }^{17}$ which could ultimately damage big buying firms. Social and environmental performance of suppliers is an area of mounting concern, and collectively, sufficient coordination between SC partners is required. SSCM is therefore in need of a closer involvement with multi tier suppliers including direct and indirect ones by establishing long-term relationships, enduring sustainability management capabilities and information sharing systems through a more structured approach.

\section{Sustainability management capabilities in upstream supply chains}

Products mature and markets change; correspondingly SCs are expected to evolve with equivalent changes in capabilities..$^{48}$ Dynamic capabilities emphasize the development of management capabilities, and difficult-to-imitate combinations of organizational, relational, technical and technological competences. Yet, this study follows the path created by Eisenhardt $\mathrm{KM}^{49}$ suggesting that dynamic capabilities per se might not be sources of sustainable advantage. According to the logic of resource-based view (RBV), sustained competitive advantage appears not only when capabilities are rare and valuable, but also when they are inimitable and non-substitutable. Correspondingly, given that dynamic capabilities are often substitutable, it could be proposed that upstream suppliers could gain the same capabilities from various paths. In this study, sustainability management capabilities, a.k.a. SMCs, refer to higher-level competences determining the company's ability to integrate, build and reconfigure internal and external resources to address and improve social and environmental performance.

To this end, SMCs are realized to be the organizational competencies that enable upstream suppliers to improve their sustainability performance. Operationalizing this definition and extending the scope in the form of triple bottom line, this study focuses on intra and inter-organizational capabilities. Within the company, product related SMCs encompass life cycle assessment practices and/ or removing hazardous substances in the chain. As for the process, SMCs are to sustain cleaner production and manufacturing processes, e.g. energy saving technologies, and source-based emission reduction practices. Across the SC, inter-organizational SMCs must also be developed with direct and indirect stakeholders. SC related SMCs could be considered the ability to motivate suppliers to be responsible and to reduce the environmental burdens caused by logistics through recycling initiatives, and stricter supplier assessments. On the whole, technical as well as relational capabilities must be ensured to sustain environmentally and socially sound relationships with external stakeholders through numerous methods.

\section{Developing sustainability management capabilities in upstream supply chains}

SMCs as well as the translation of these capabilities into specific programs highly depend on the evaluation of top managements of the extent to which external factors could be a threat. When a supplier develops SMCs, upstream level could be a bridge between external stakeholder assessments and internal operational changes. In this sense, the attitude of stakeholders toward sustainability and the commitment of buying firms to social and environmental issues form corporate strategies. ${ }^{22}$ Build a coherent model to show elements necessary to create SSCM. Yet, what is not tested is how social and environmental management practices could translate to actors, such as second movers, commodity suppliers or the entire industry. Afterwards,${ }^{50}$ further examine how organizations could deal with short-term pressures to remain economically feasible while pursuing SSCM. Subsequently, they propose configurations of environmental behaviours as well as business strategies. Nevertheless, social aspect of sustainability is not covered within the study. However, an inclusive analysis of sustainable operations must consider all three dimensions simultaneously. Additionally, ${ }^{17}$ examine drivers and enablers, which could foster environmental management capabilities (EMCs) in small and medium sized suppliers. Despite the relevancy and accuracy of the findings, the consequences of the improved EMCs of suppliers and the ways that both buying firms and the suppliers could benefit from sustainability management are yet to be examined..$^{15}$ Further synthesize a model to address accountability for sustainability issues in SCs. Sustainable evaluation and verification (SEV) model, containing all activities that identify key metrics, process data, verify reliability and disclose the information of sustainability performance to all stakeholders, brings satisfactory results. But it does not address how local firms could leverage inclusivity to enhance SSCM development. Respectively, it becomes important to present a holistic view to monitor environmental and social performance through stakeholder unification. In accordance with what ${ }^{17}$ previously address as influential, this study identifies two critical groups that are instrumental in SMC development, namely buying firms' strategy and external factors.

Buying firms' strategy: The economic influence of the fashion company, which is the buying firm, on the supplier's results in leveraged price negotiations due to greater market power. Synergetic links might emerge in the form of pro-active buyer-supplier relationships, resource acquisition and development of SMCs. Buying firms could appraise their suppliers' outputs in reference to sustainability performance indicators since companies, which excel at monitoring could secure and use information to further continuous improvement in a supplier's processes to maintain quality while reducing costs. ${ }^{48}$ 
Besides, buying firms' direct involvement in activities has a direct influence on the achievement of significant environmental and operational performance improvement by the supplier. ${ }^{17}$ In this vein, buyer-supplier relations progressively involve attention to integration, partnership and collaboration.

External factors: External drivers, e.g. national and international government, safety requirements, and society could provide an impulse to acquire resources to deploy SMCs. Market drivers, e.g. customers, industry associations, and competitors could stimulate environmental initiatives. In particular, institutional pressures drive manufacturing firms to adopt internal environmental practices that in turn relate to external adoption of green practices. ${ }^{31}$ Thus, standards introduced by the regulation and corresponding changes are flowed back upstream. The development of SMCs should be integrated into organizational logics because these considerations affect the companies' decisions by focusing on the execution toward a set of issues consistent with the dominant logic. Earlier research provides a static view in which upstream suppliers are expected to meet legal requirements. Yet, a more dynamic perspective is needed to examine how dynamic organizational behaviour could be developed through SMCs in the context of social and environmental aspects to relate them to consequences on operational performance.

\section{Consequences of sustainability management capabili- ties on performance}

Integrating environmentally and socially sound behaviours, developing SMCs and transformation the entire SC in efforts to become more sustainable is challenging. Strategic decisions with significant environmental and social goals require significant resources. Operations management (OM) literature often illustrates a positive connection between environmental practices and financial outcomes. ${ }^{51}$ Address that improved environmental, health and safety performance could help plant-productivity efforts and increase market share and revenues. Further, environmental management systems could result in profitability improvement mainly due to the enhancement in cost efficiency, measured by return on sales. ${ }^{52}$

Total quality environmental management perspective, on the other hand, sees a strong association between quality management systems and environmental management systems. ${ }^{50,27}$ Similarly demonstrates that environmental initiatives have a positive influence on a plant's quality, delivery, flexibility and cost performance. The findings of ${ }^{53}$ further express that it is vital to consider supply-side and demandside sustainability-related collaboration as this could correspond to superior market and sustainability performance. From the inbound point of view, greening SCs could bring numerous benefits to a company such as cost reduction, and integrating suppliers in a participative decision making process could endorse environmental innovation. ${ }^{18}$ Undoubtedly, upstream suppliers are instrumental in complementing SMCs of their downstream partners by providing sustainable inputs and facilitating prevention processes.

Nonetheless, despite accumulating evidence that sustainability is a contributor to overall performance, several authors suggested that the connection might be more complicated than a direct impact. For example, not all environmental practices might bring cost savings since some practices increase costs, especially in the short term $;{ }^{50}$ e.g. proactive investments in green technology might not pay off for some time. Further, the findings of ${ }^{54}$ suggest that that adoption of lean production systems do not necessarily engage in less onsite treatment. ${ }^{55}$ Argue that managers without a strategic understanding of social responsibility could generate greater costs when the company is later judged to have violated its social obligation.

These curious yet inconclusive results require further investigation of the association between SMCs and consequences on operational and organizational performance. An integrated framework encapsulating dynamic capabilities as constituents of a corporate behaviour is needed and this study therefore aims to explore aforementioned issues with an attempt to provide comprehensive insights on the move toward making fashion SCs truly sustainable.

\section{Research methodology}

\section{Research questions}

Given abovementioned research gaps, this study aims to interrogate the following points.

a. RQ1: Which are the drivers for suppliers to develop and deploy SMCs?

b. RQ2: Which are the components to conceptualize an integrated model for sustainability management at upstream levels?

c. RQ3: How do SMCs affect operational and organizational performance?

\section{Research method}

This study opts to focus on the development and deployment of SMCs within upstream suppliers. With the unit of analysis being a supplier firm, the principles of theory building based on exploratory case study methodology have been implemented. ${ }^{56}$ Given that we explore a relatively new research area, case study research is deemed appropriate.

\section{Sampling}

A theoretical sampling approach was pursued in order to understand conceptual differences and to increase generalization of the findings. Comparability of the cases was ensured through the introduction of a number of selection criteria. In order to reduce contingency effects, such as cultural differences, we focused on a single country, Italy, which emerges as one of the most significant countries for upstream luxury fashion industry. EUROPAGES, available via http://www. europages.co.uk, shows that approximately $30 \%$ of the global silk production and supply comes from Italy. Similarly, Italy holds a significant $43 \%$ of the global leather production.

Furthermore, to investigate diversification in organizational characteristics and buying firm-supplier-supplier relationship we focused on two SC levels, namely first level and second level suppliers. Buying firms, on the other hand, were also carefully examined. To this end, we first set out to select luxury fashion companies with leading sustainability practices so that the propositions will have practical value for other companies. We identified these leading companies from the membership list of corporate sustainability initiatives, such as United Nations Global Compact, Global Reporting Initiative and Carbon Disclosure Project, and corporate websites, where performance disclosures were addressed. According to their performance results in sustainability and organizational commitment to environmental and social issues, two buying firms were chosen. Buyer X provides proactive engagement and collaborative actions. Buyer Y, on the other 
hand, places emphasis on stakeholder engagement. Subsequently, we focused on these two buying firms' first and second level suppliers to examine SMCs at the upstream level.

We identified the initial pool of 11 small and medium sized Italian

Table I Sample Companies' Characteristics upstream suppliers located in Lombardy region of Italy. Eventually, data collected from seven suppliers were used. As previously suggested, seven cases are adequate for theory-development ${ }^{57}$ as it allows to generalize while remaining cognitively manageable for qualitative analysis. Table 1 profiles the participants in this study.

\begin{tabular}{|c|c|c|c|c|c|c|c|}
\hline & \multicolumn{7}{|l|}{ Cases } \\
\hline & $\mathbf{A}$ & B & C & D & $\mathbf{E}$ & $\mathbf{F}$ & $\mathbf{G}$ \\
\hline Products & Cashmere, silk & $\begin{array}{l}\text { Cotton, wool } \\
\text { fabrics }\end{array}$ & $\begin{array}{l}\text { High quality } \\
\text { bags }\end{array}$ & $\begin{array}{l}\text { Small leather } \\
\text { goods }\end{array}$ & $\begin{array}{l}\text { Silk, cashmere, } \\
\text { wool }\end{array}$ & $\begin{array}{l}\text { Leather for } \\
\text { bags and } \\
\text { shoes }\end{array}$ & Leather \\
\hline Level in SC & $\left.\right|^{\text {st }}$ level & I $^{\text {st level }}$ & $\left.\right|^{\text {st }}$ level & $\left.\right|^{\text {st }}$ level & $2^{\text {nd }}$ level & $2^{\text {nd }}$ level & $2^{\text {nd }}$ level \\
\hline Employees & 48 & 45 & 85 & 50 & 70 & 96 & 180 \\
\hline Foundation & |96I, Italy & I884, Italy & 1986, Italy & I978, Italy & 1973, Italy & I958, Italy & I944, Italy \\
\hline $\begin{array}{l}\text { Manufacturing } \\
\text { process }\end{array}$ & $\begin{array}{l}\text { Sourcing, } \\
\text { modelling, } \\
\text { cutting, } \\
\text { assembly, } \\
\text { quality control }\end{array}$ & $\begin{array}{l}\text { Knitting, cutting, } \\
\text { pressing, quality } \\
\text { control }\end{array}$ & $\begin{array}{l}\text { Modelling, } \\
\text { cutting, } \\
\text { semi-finished } \\
\text { products, } \\
\text { assembly, } \\
\text { quality control }\end{array}$ & $\begin{array}{l}\text { Modelling, } \\
\text { cutting, semi- } \\
\text { finished } \\
\text { products, } \\
\text { assembly, quality } \\
\text { control }\end{array}$ & & $\begin{array}{l}\text { Design, dyeing, } \\
\text { finishing, } \\
\text { bonding, } \\
\text { quality control }\end{array}$ & $\begin{array}{l}\text { Design, dyeing, } \\
\text { finishing, } \\
\text { bonding, } \\
\text { quality control }\end{array}$ \\
\hline Buying Firm & $\begin{array}{l}\text { Directly Buyer } \\
X, Y\end{array}$ & $\begin{array}{l}\text { Directly Buyer } \\
Y\end{array}$ & $\begin{array}{l}\text { Directly Buyer } \\
X\end{array}$ & $\begin{array}{l}\text { Directly Buyer } \\
\text { X }\end{array}$ & $\begin{array}{l}\text { Indirectly Buyer } \\
Y\end{array}$ & $\begin{array}{l}\text { Indirectly } \\
\text { Buyer X,Y }\end{array}$ & $\begin{array}{l}\text { Indirectly } \\
\text { Buyer Y }\end{array}$ \\
\hline
\end{tabular}

\section{Data collection}

The interview protocol was created subsequent to a comprehensive literature review that resulted in the generation of theoretical constructs. To this end, a semi-structured approach was pursued to evaluate each company and relevant SMCs to explore the consequences on operational performance.

In 2014, the research team held the interviews with managers in charge of operations, product design and sustainability with a final goal of understanding each company's posture in terms of environmental and social sustainability. What must be stated is that sustainability appears to be such a broad topic, which has been integrated into a number of job descriptions of multiple managers. Hence, some managers had multiple responsibilities. This indeed reduced the number of the interviews conducted yet increased the quality of the findings.

Each interview lasted between 60 and 90minutes. Archival documents were also reviewed to triangulate the responses. The greater sophistication on environmental and social issues of buying firms encouraged the research team to review formal policies, published sustainability and financial reports.

\section{Data analysis}

The transcripts, interviewer notes and secondary data was compiled in a set, and the coding process was completed via a multistep iterative process. Firstly, within-case analysis was conducted, which allowed the study to gain a broad understanding of the sustainability strategy deployed at each company, the role of environmental and social management in value proposition, and the impact on operational performance. Besides, each case analysis explored how suppliers incorporate environmental and social initiatives in their decisionmaking, and the actual role of buying firm on the development of SMCs.

Subsequent to within-case analysis, cross-case analysis was employed to identify common themes. Categorization and pattern matching techniques were employed to reduce data and to identify the main components of a SSCM through multiple SMCs across sample companies. Eventually, a coherent understanding of the development of SMCs and their consequences emerged. Consequently, the main research findings were derived and are presented in the next section.

\section{Results and findings}

\section{A holistic framework of sustainability management capabilities and performance}

In this section, the findings are synthesized across seven cases. SMCs emphasize the development of difficult to imitate combinations of organizational, relational, technical and technological competences. This study further points two interrelated clusters: practical SMCs and interactive SMCs developed and deployed at first and second levels.

Practical SMCs at upstream supply chains: The observations of both buying firms' direct suppliers and direct suppliers' subcontractors are channelled. Practical capabilities, in this context, are the set of intraorganizational routines based on an understanding of the technology involved in product design and manufacturing phases. Practical capabilities are emphasized to display how suppliers could improve their abilities to provide more environmentally and socially conscious products, and to hold a cleaner manufacturing process. Starting from the first level suppliers, Case B was seeking to improve the quality of their products through more innovative techniques. Case B, working with both Buyer X and Buyer B, was motivated by its buying firms to develop intra-capabilities to develop new products containing no harmful substances. Similarly, Case D established formal procedures to consider the environmental performance of new products. Buyer X has been established a collaborative strategy with Case D by which 
Case D initiated incremental actions. When it comes to the second level suppliers, what must be stressed is that top management of the second level suppliers were found more committed to sustainability. Low-hanging fruit situation was not observed in any of the cases since three cases further advanced SMCs in the product development phase as a consequence of higher ethical consciousness. Case E implemented rigorous environmental and social certifications in its facilities. To this end, formal procedures were established in order to consider the environmental performance and the uniformity was secured toward a reduction in the environmental impact. Case F and Case G, on the other hand, invested in the development of new products containing no hazardous materials. Table 2 displays what SMCs were deployed with respect to product improvement.

Table 2 Practical SMCs for Product Improvement

\begin{tabular}{|c|c|}
\hline \multicolumn{2}{|c|}{ Practical SMCS-product improvement } \\
\hline \multicolumn{2}{|c|}{ Ist Level suppliers } \\
\hline Case B & $\begin{array}{l}\text { Identifying new innovative technologies to improve } \\
\text { product quality }\end{array}$ \\
\hline & $\begin{array}{l}\text { Investing in the development of new products with no } \\
\text { hazardous substances }\end{array}$ \\
\hline Case C & $\begin{array}{l}\text { Actively controlling over the production cycle to } \\
\text { monitor harmful substances }\end{array}$ \\
\hline Case D & Assessing environmental considerations \\
\hline \multicolumn{2}{|c|}{$2^{\text {nd }}$ Level suppliers } \\
\hline Case E & Assessing ethical aspects for the life cycle \\
\hline Case F & Monitoring and eliminating hazardous materials \\
\hline Case G & $\begin{array}{l}\text { Establishing formal procedures to eliminate toxic } \\
\text { materials }\end{array}$ \\
\hline
\end{tabular}

In terms of practical SMCs for the process improvement, Case A utilized innovative techniques to reduce negative impact while generating higher quality materials. Case B and Case D internally worked to enhance waste management procedures, and consequently waste reduction methodologies were adopted. The environmental stewardship and organizational efforts of Buyer X motivated Case D to develop greener changes in the ownership. Source-based emission reduction was achieved through collaborative actions. Furthermore, bonding phase in the manufacturing process was optimized and completely robotised to reduce the overall ecological footprint. As for the second level suppliers, Case E and Case F worked closely with their buying firms, that is, first level suppliers, and improved sustainability performance results were achieved. In the same direction, these suppliers deeply embarked sustainable production techniques as selection criterion to select their own subcontractors. Case E became a supplier with certified environmental and quality management systems, and they further adhered to global standardizations on chemicals. Case F, correspondingly, opted for deploying new machines to improve product quality, increase the efficiency of human capital, and ultimately reduce environmental impact; thus, pollution prevention was achieved. Case $\mathrm{G}$ installed a biological wastewater treatment plant to ensure that discharged water would not need any further purification technique to be diluted. Additionally, Case F and Case G, implemented green procurement policies and environmental criteria into their supplier selections. Table 3 displays what SMCs were deployed with respect to the process improvement at both first and second level suppliers at upstream FSCs.
Table 3 Practical SMCs for Process Improvement

\begin{tabular}{|c|c|}
\hline \multicolumn{2}{|c|}{ Practical SMCs-process improvement } \\
\hline \multicolumn{2}{|c|}{ | ${ }^{\text {st }}$ level suppliers } \\
\hline \multirow[t]{3}{*}{ Case A } & $\begin{array}{l}\text { Initiating new technologies to generate high quality } \\
\text { materials }\end{array}$ \\
\hline & Installing energy saving techniques \\
\hline & Developing strategies for water conservation \\
\hline \multirow[t]{2}{*}{ Case B } & Source-based emission reduction \\
\hline & Investing in waste management \\
\hline \multirow[t]{3}{*}{ Case $\mathrm{C}$} & Installing energy saving technologies \\
\hline & Advancing waste management \\
\hline & $\begin{array}{l}\text { Seeking innovative new techniques to adopt preventive } \\
\text { approaches }\end{array}$ \\
\hline \multirow[t]{4}{*}{ Case D } & $\begin{array}{l}\text { Rethinking the approach for waste management for a } \\
\text { cleaner production }\end{array}$ \\
\hline & Process optimization \\
\hline & Source-based emission reduction \\
\hline & $\begin{array}{l}\text { Robotised bonding technique to reduce ecological } \\
\text { footprint }\end{array}$ \\
\hline \multicolumn{2}{|c|}{$2^{\text {nd }}$ level suppliers } \\
\hline \multirow[t]{3}{*}{ Case $\mathrm{E}$} & $\begin{array}{l}\text { Innovative techniques to reduce environmental impact, } \\
\text { improve quality and efficiency Pollution prevention }\end{array}$ \\
\hline & $\begin{array}{l}\text { Active management of quality as well as environmental } \\
\text { systems }\end{array}$ \\
\hline & Adherence to global standards on chemicals \\
\hline \multirow[t]{4}{*}{ Case $\mathrm{F}$} & Adopting preventive approaches \\
\hline & Energy saving technologies \\
\hline & Source based emission reduction \\
\hline & Improving the performance on water conservation \\
\hline \multirow[t]{3}{*}{ Case G } & Establishing procedures for the emission reduction \\
\hline & Environmental friendly production processes \\
\hline & $\begin{array}{l}\text { Proactive management of a biological wastewater } \\
\text { treatment plant }\end{array}$ \\
\hline
\end{tabular}

Developing less polluting manufacturing techniques and providing safer working conditions require technical expertise. Continuous learning and know-how transfer must be ensured along the SCs to enable suppliers to improve product quality and to fully integrate sustainability into their processes.

Interactive SMCs at upstream supply chains: Interactive capabilities consist of the ability to design informal mechanisms to align activities, share information, enhance commitment and set common goals between the company and other actors in the chain. At the first level suppliers, Case A, in particular, invested in the improvement of working conditions and labour safety practices. In this sense, Case A and Case B established formal procedures and provided regular training activities and educational programs at the organizational level. Case $\mathrm{C}$, on the other hand, was seeking to redesign their organizational processes for a better assignment of responsibilities among the departments. The second level suppliers, 
similarly, established extensive training activities to embark on ethical standpoints within the organization. Particularly, Case E and Case G exhibited concerns about the social and environmental aspects; hence they participated in many training activities to secure a more ethically sound organizational culture. Buyer Y motivated Case F to develop greener changes at the organizational level. Thus, it could be stressed that social and environmental changes in the ownership are likely to get driven by the buying firms' strategies. Auditing and tracking emerged as important strategies to forge effective partnerships between suppliers. Table 4 displays what interactive SMCs were at the organizational level within both first and second level suppliers.

Table 4 Interactive SMCs at Organizational Level

\begin{tabular}{|c|c|}
\hline \multicolumn{2}{|c|}{ Interactive SMCs-organizational level } \\
\hline \multicolumn{2}{|c|}{ It level suppliers } \\
\hline \multirow[t]{3}{*}{ Case A } & Health and safety practices Improve working environment \\
\hline & Labour safety practices \\
\hline & Education programs \\
\hline \multirow[t]{2}{*}{ Case B } & Training activities \\
\hline & Safety practices \\
\hline \multirow[t]{2}{*}{ Case C } & Knowledge sharing \\
\hline & $\begin{array}{l}\text { Redesigning organizational processes for a better assignment } \\
\text { of responsibilities }\end{array}$ \\
\hline \multicolumn{2}{|c|}{$2^{\text {nd }}$ level suppliers } \\
\hline \multirow[t]{2}{*}{ Case $\mathrm{E}$} & Effective training activities \\
\hline & Top management commitment \\
\hline Case $\mathrm{F}$ & Organizational education activities \\
\hline Case G & Top management commitment and organizational culture \\
\hline
\end{tabular}

Consistently, implementing interactive SMCs at the SC level is critical. To this end, Case B began to rethink their approach to share information with SC members. Buyer X undertook improvement initiatives that delivered resource efficiency, and to this end Case $\mathrm{C}$ collaborated with Buyer X to obtain improved performance results in terms of process and resource efficiency. Similarly, Case D conveyed a procedure to monitor their subcontractors through long lasting relationship with their tanneries through formal measures and protocols. Buyer X urged Case C and Case D to participate in environmental protection programs to secure resource based emission reduction. Furthermore, Case D created a network to support, encourage and endorse environmentally and socially sound leather production. As for the second level suppliers, Case E and Case F invested in the procurement of products and services with no potentially harmful substances. Being a supplier with a certified environmental and quality management system, Case E fostered its organizational efforts to improve data management and encourage its own subcontractors to adhere to regulations. Reporting on chemicals and managing the disclosure of environmental claims to external stakeholders were observed as ongoing-yet to be improved-business practices. Case G demonstrated the importance of the top management commitment. Table 5 displays interactive SMCs at first and second level suppliers.

Interactive SMCs are directly associated with sharing information, setting common goals, monitoring, and transferring knowledge. Development and use of social and environmental metrics, auditing and performance tracking must be considered imperative. Interactive
SMCs are authoritative to emphasize common goals rather than differences. Companies could ensure positive upstream social and environmental performance through strong interactive SMCs.

Table 5 Interactive SMCs at Supply Chain Level

\begin{tabular}{|c|c|}
\hline \multicolumn{2}{|c|}{ Interactive SMCs-supply chain level } \\
\hline \multicolumn{2}{|c|}{ I $^{\text {st }}$ level suppliers } \\
\hline \multirow[t]{2}{*}{ Case B } & $\begin{array}{l}\text { Motivating suppliers to be environmentally and socially } \\
\text { responsible }\end{array}$ \\
\hline & $\begin{array}{l}\text { Managing environmental and social claims. Participation } \\
\text { of philanthropic activities }\end{array}$ \\
\hline \multirow[t]{3}{*}{ Case C } & Adoption of sustainable supplier selection criteria \\
\hline & Adoption of a program to improve quality \\
\hline & Collaborative relations with the buying firm \\
\hline \multirow[t]{3}{*}{ Case D } & Monitoring subcontractors based on their social records \\
\hline & $\begin{array}{l}\text { Lasting relationships with tanneries. Participation in } \\
\text { environmental protection program with the buying firm }\end{array}$ \\
\hline & $\begin{array}{l}\text { Creation of a network for environmentally and socially } \\
\text { sound leather production }\end{array}$ \\
\hline \multicolumn{2}{|c|}{$2^{\text {nd }}$ level suppliers } \\
\hline \multirow[t]{3}{*}{ Case $\mathrm{E}$} & $\begin{array}{l}\text { Requirements to select suppliers in accordance with } \\
\text { standards on chemicals }\end{array}$ \\
\hline & Active management of quality and environmental claims \\
\hline & Local community development activities \\
\hline \multirow[t]{3}{*}{ Case F } & $\begin{array}{l}\text { Encourage suppliers to be more responsible and to } \\
\text { reduce negative impact }\end{array}$ \\
\hline & Monitoring suppliers \\
\hline & Reporting on substances and chemicals \\
\hline Case G & Providing sponsorships for educational projects \\
\hline
\end{tabular}

The consequences of SMCs on the operational performance: This study extends the SC literature by defining SMCs from internal and external perspectives and by linking them to the operational performance. The main dimensions of SMCs examined in this study are broader in scope, which is encompassing social and environmental dimensions. Innovation capabilities emerged as an important operational outcome through SMCs. Case A, Case B and Case D initiated installing new technologies to improve product quality and process efficiency. In this vein, Case D began to use totally a robotised bonding technique in its manufacturing process, and Case B invested in a technique to remove hazardous substances from its products. Prior research hypothesized the relationship between innovativeness and sustainability being mono-directional, implying that innovativeness leads to higher sustainability. Yet, our results show that SMCs can also lead to higher innovativeness. Pollution prevention techniques, audits and advanced standards along with cleaner production techniques not only improved sustainability performance but also introduced new innovation competences. Case A, Case F and Case G improved SC relationships and customer satisfaction due to improved results in energy saving, waste management and preventive approaches.

It was also found that eliminating hazardous materials, pollution prevention, and impact assessment formed responsible governance, which was found cultivating the corporate culture. Case E, in particu- 
lar, achieved a good level of employee loyalty by generating a cohesive working environment through adhering to quality and environmental standards, and employing numerous training programs; e.g. improved health and safety performance resulted in lower absence rates and work related accidents. Practical SMCs with a rethinking approach for a cleaner production, and interactive SMCs through collaborative actions must be ensured to secure improved organizational and operational outcomes. On the whole, as depicted in Figure 1, practical and interactive SMCs are positively associated with organizational and operational performance areas.

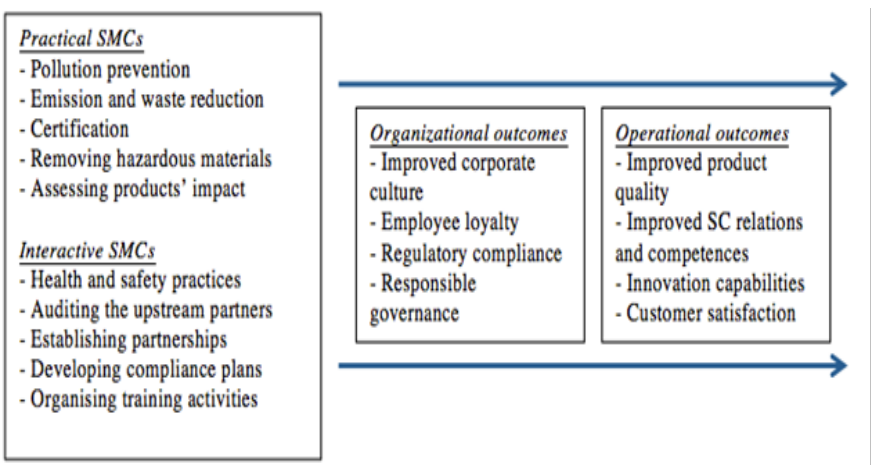

Figure I The Consequences of SMCs on Performance.

The clarification of the consequences of SMCs on different performance dimensions is significant to extend the comprehension of SSCM research. On the one hand, dynamic capabilities were not united as an aggregated construct in this study; on the contrary, they were incorporated as various SMC dimensions simultaneously. On the other hand, considering the inherent complexity of FSCs, operational performance in this study was not measured as a combination of several dimensions. Thus, organizational and operational impact of SMCs on multi-dimensional business performance was analysed. The results enrich the understanding of how practical and interactive SMCs could affect business performance in terms of corporate governance, customer satisfaction, innovation, loyalty and quality. Our study clearly addresses that practical SMCs on product and process as well as interactive SMCs on organizational and SC levels are significantly and directly associated with operational performance. Results address that practical SMCs facilitating pollution prevention, waste management and hazardous material removal could simultaneously improve corporate culture, regulatory compliance and stakeholder relationships. Further, suppliers that implement such initiatives could also improve product quality and innovation capabilities. Besides, interactive SMCs facilitating health and safety practices, audits, deepened compliance plans and training activities could lead to enhanced stakeholder relations, employee loyalty and a well-managed corporate culture while improving customer satisfaction. The findings also suggest that manufacturers with the broadest arcs of sustainability integration with upstream suppliers and downstream customers could achieve higher levels of the business performance.

\section{Discussion and research propositions}

Drawing the first and second level suppliers' capabilities and relating them to the operational performance unveiled some potential causal linkages that could have significant academic and managerial implications. This study suggests three propositions to be the basis for further theory development.

\section{Drivers of the development of SMCs at upstream sup- ply chains}

Regulatory compliance: First level suppliers felt a direct external legislative pressure. For example, Buyer Y largely influences its direct suppliers to develop SMCs; yet it was found that regulatory compliance was the main driver for Case B to deploy SMCs. Similarly, Case $\mathrm{C}$ and Case D implemented numerous internal and external practices as a response to regulatory compliance. All first level supplier companies progressively improved their environmental performance over the years. Case A developed techniques for water conservation to meet the requirement set by laws. Similarly, Case B and Case C intensely worked on waste management. Case D, whereas, emerged as the case where interactive SMCs at the SC level were gradually improved. Buying luxury fashion firms are influential and they adopt sustainability management practices, including green procurement, fair trade principles, and sustainable sourcing. Their suppliers, therefore, need to get prepared for what management of their buying firms would further require. Buying fashion firms face strong scrutiny from activists, customers, and organisations; hence, their direct suppliers are required to strictly comply with regulations. These observations lead to the following propositions:

a. Proposition 1A: First level suppliers feel a bigger pressure for regulatory compliance since their buying firms directly encounter intense scrutiny

b. Proposition 1B: Regulatory compliance emerges as a critical driver to further develop SMCs and it becomes a tighter customer requirement to be passed upstream in the SC

Internal commitment: At the second level, all suppliers, Case E, $\mathrm{F}$ and $\mathrm{G}$, felt a great extent of internal commitment to improve their sustainability performance. Top management of these firms began to examine innovative trends in production to increase process efficien$\mathrm{cy}$, and to reduce the environmental impact. Senior management team of Case $\mathrm{G}$ paid close attention environmental issues such as emission reduction and hazardous substance elimination. Case E, on the other hand, proved an internal commitment by gradually improving its data management. Case $\mathrm{F}$ fostered technological innovations to for hazardous material elimination. Nevertheless, it must be addressed that top management's effect on SMC building was somehow limited at the SC level. Despite the efforts and gradual improvement, social aspects must be reinforced. Undoubtedly, it could be stressed that development of product and process related practical capabilities are less time and resource intensive than the development of external capabilities at the SC level. Nonetheless, efforts must be improved to reinforce practical and interactive capabilities simultaneously to improve overall social and environmental performance. This finding suggests the following propositions:

i. Proposition 2A: Internal commitment coming from the top management is positively associated with the development of practical and interactive SMCs in the upstream SCs

ii. Proposition 2B: The development of practical and interactive SMCs requires a proactive communication among all upstream $\mathrm{SC}$ members

\section{Taking an environmental and social impact free stance}

Oxford dictionary defines the stance as 'the attitude of an organization towards something'. In this context, this study suggests 
that an environmental and social impact free stance, encompassing practical and interactive SMCs could improve operational and organizational performance. The impact free stance emphasizes that buying firms and suppliers must develop and deploy SMCs that would lead to organizational and operational performance improvements. The stance could be affirmed through a business model where economic goals are compatible with environmental and social targets. This could be accomplished when sustainability becomes a part of the dayto-day conversation. Responsibility to take such a proactive stance requires sharing responsibility for social and environmental concerns across the upstream SCs. To this end, fashion companies are strongly suggested to develop their own standards and monitor their suppliers' compliance rather than rely on third party standards. Know-how is an important capability that must be transferred for which collaboration and knowledge exchange must be ensured at upstream levels. Taking the impact-free stance could facilitate information sharing across functional areas to improve product and process designs that are instrumental for cost reduction, product quality improvements and customer satisfaction. These findings, therefore, suggest the following propositions:

a. Proposition 3A: Practical and interactive SMCs must be developed simultaneously to result in positive performance outcomes

b. Proposition 3B: The development and deployment of SMCs are directly and positively associated with operational performance improvements in terms of product quality, innovation capabilities and customer satisfaction

c. Proposition 3C: The development and deployment of SMCs are directly and positively associated with organizational performance improvements in terms of corporate culture, employee loyalty and regulatory compliance

Finally, the conceptual structure emerging from seven case studies are depicted in Figure 2.

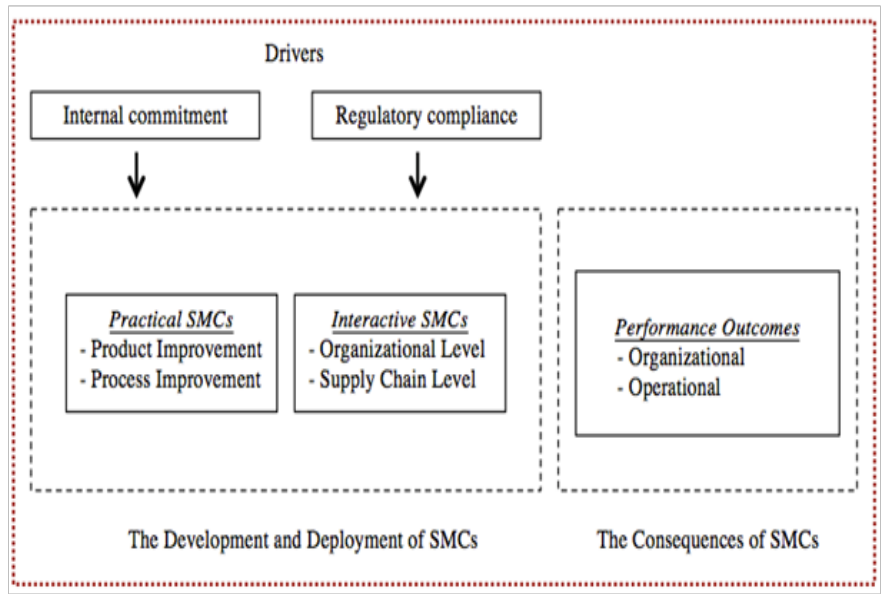

Figure 2 The Environmental and Social Impact Free Stance.

\section{Conclusion}

This study develops a framework by considering how practical and interactive SMCs must be developed and deployed to improve operational and organizational performance. This exploratory, casebased research has a number of proactive implications for SC theories.

Personal luxury goods are designed, manufactured, distributed and sold throughout a number of suppliers. Product components coming from a number of suppliers are strictly controlled to ensure hazardous substance neutral products. Nonetheless, some other crucial issues in the upstream SCs could emerge about human rights. Hence, monitoring a multitude of upstream suppliers' behaviour is fundamental despite its cost and execution challenges. Due to the length of global FSCs, the vulnerability could arise from both technical and relational aspects, e.g. how products were produced and delivered, and to what extent social necessities were fulfilled. In this sense, a broader set of precautions that would protect buying firms and suppliers in the upstream SC must be considered. Furthermore, from a capabilities perspective, managing suppliers in the upstream and consumers in the downstream could be considered complementary and they could indeed reinforce each other. This expanded foundation requires a further integration in response to social and environmental issues.

Transparency could enable companies to have a comprehensive and longitudinal picture of where they currently stand and to what extent progress could be advanced. The broad scale impact of social and environmental issues within public and private domains implies that an effective coordination is required to create efficient, accountable and sustainable SCs. As a member of the community where its business is established, a company must consider the well being of broader components in the industrial, social and ecological system.

The major managerial implication of this study is that fashion companies could acquire an effective and comprehensive sustainability strategy toward the impact free stance, which requires upstream suppliers implementing social and environmental management initiatives, developing practical and interactive capabilities and working jointly, to attain organizational and operational performance improvements. Future research can explore many avenues though. As a methodological note, it can be seen that the conceptual framework as a step in theory building, but is not inevitably a final product. Thus, our propositions must go through the various stages of validation and tested before being considered a theoretical framework.

\section{Acknowledgments}

None.

\section{Conflict of interest}

Author declares there is no conflict of interest in publishing the article.

\section{References}

1. Caniato F, Caridi M, Crippa L, et al. Environmental sustainability in fashion supply chains: An exploratory case based research. Inter $J$ Production Economics. 2012;135(2):659-670.

2. Jørgensen MS, Jensen CL. The shaping of environmental impacts from Danish production and consumption of clothing. Ecological Economics. 2012;83:164-173

3. Ditty S. It's time for a fashion revolution. United Kingdom; 2015. p. $1-17$.

4. Lueg R, Pedersen MM, Clemmensen SN. The role of corporate sustainability in a low-cost business model-A case study in the Scandinavian fashion industry. Business Strategy \& Environment. 2013;24(5):344-359.

5. WWF. Cotton: Sustainable Agriculture. 2014.

6. Aiama D, Carbone G, Cator D, et al. Biodiversity Risks and Opportunities in the Apparel Sector. Gland; 2016. p. 1-41. 
7. Rissanen TI. Creating fashion without the creation of fabric waste. In: Ulasewicz C, Hethorn J, editors. Sustainable fashion: Why now? A conversation about issues, practices, and possibilities. Fairchild Books, USA; 2008. p. 184-207.

8. Nagurney A, Yu M. Sustainable fashion supply chain management under oligopolistic competition and brand differentiation. Inter J Production Economics. 2012;135(2):532-540.

9. Ecotextiles. Estimating the carbon footprint of a fabric. 2011.

10. Perry P, Wood S, Fernie J. Corporate social responsibility in garment sourcing networks: Factory management perspectives on ethical trade in Sri Lanka. J Business Ethics. 2015;130(3):737-752.

11. Theuws M. Hidden subcontracting in the garment industry. Amsterdam, Europe; 2015.

12. Clean Clothes Campaign(a). Global brands leave Cambodian workers fainting over fashion. 2015.

13. Clean Clothes Campaign(b). Mulberry slammed for worker exploitation at Turkish factory. 2015.

14. Moulds J. Child labour in the fashion supply chain. The Guardian. 2015.

15. Gualandris J, Klassen RD, Vachon S, et al. Sustainable evaluation and verification in supply chains: Aligning and leveraging accountability to stakeholders. J Operations Management. 2015;38:1-13.

16. Tachizawa EM, Wong CY. Towards a theory of multi-tier sustainable supply chains : a systematic literature review. Supply Chain Management: An Inter J. 2014;19(5/6):643-663.

17. Lee SY, Klassen RD. Drivers and Enablers That Foster Environmental Management Capabilities in Small-and Medium-Sized Suppliers in Supply Chains. Production \& Operations Management. 2008;17(6):573-586.

18. Yu W, Chavez R, Feng M, et al. Integrated green supply chain management and operational performance. Supply Chain Management: An Inter J. 2014;19(5/6):683-696.

19. Huo B, Qi Y, Wang Z, et al. The impact of supply chain integration on firm: The moderating role of competitive strategy. Supply Chain Management: An Inter J. 2014;19(4):369-384.

20. Zhu Q, Cote RP. Integrating green supply chain management into an embryonic eco-industrial development: A case study of the Guitang Group. J Cleaner Production. 2004;12(8-10):1025-1035.

21. Zhu Q, Sarkis J, Lai K. Green supply chain management implications for "closing the loop". Transportation Research Part E. 2008;44(1):1-18.

22. Pagell M, Wu ZH. Building a more complete theory of sustainable supply chain management using case studies of 10 exemplars. J Supply Chain Management. 2009;45(2):37-56.

23. Castaldo S, Perrini F, Misani N, et al. The Missing Link Between Corporate Social Responsibility and Consumer Trust: The Case of Fair Trade Products. Journal of Business Ethics. 2008;84(1):1-15.

24. Lozano R, Huisingh D. Inter-linking issues and dimensions in sustainability reporting. J Cleaner Production. 2011;19(2-3):99-107.

25. Ageron B, Gunasekaran A, Spalanzani A. Sustainable supply management: An empirical study. Intern $J$ Production Economics. 2012;140(1):168-182.

26. Jia P, Govindan K, Choi TM, et al. Supplier selection problems in fashion business operations with sustainability considerations. Sustainability J. 2015. p. 1603-1619.

27. Schoenherr T. The role of environmental management in sustainable business development: A multi-country investigation. Inter J Production Economics. 2012;140(1):116-128.
28. Schaltegger S, Burritt R. Measuring and managing sustainability performance of supply chains: Review and sustainability supply chain management framework. In: Burr R, editor. Supply Chain Management: An Inter J. 2014;19(3):232-241.

29. Beske P, Seuring S. Putting sustainability into supply chain management. In: Burr R, editor. Supply Chain Management: An Inter J. 2014;19(3):322-331

30. Gimenez C, Sierra V, Rodon J. Sustainable operations: Their impact on the triple bottom line. Inter J Production Economics. 2012;140(1):149-159.

31. Zhu Q, Sarkis J, Lai K. Institutional-based antecedents and performance outcomes of internal and external green supply chain management practices. J Purchasing \& Supply Management. 2013;19(2):106-117.

32. Ahi P, Searcy C. A comparative literature analysis of definitions for green and sustainable supply chain management. J Cleaner Production. 2013;52:329-341.

33. Seuring S, Müller M. From a literature review to a conceptual framework for sustainable supply chain management. J Cleaner Production. 2008;16(15):1699-1710.

34. Curwen LG, Park J, Sarkar AK. Challenges and solutions of sustainable apparel product development: A Case Study of Eileen Fisher. Clothing \& Tex Res J. 2013;31(1):32-47.

35. Shen B. Sustainable fashion supply chain: Lessons from H\&M. Sustainability J. 2014;6(9):6236-6249.

36. Lee CKM, Lam JSL. Managing reverse logistics to enhance sustainability of industrial marketing. Industrial Marketing Management. 2012;41(4):589-598.

37. Ciliberti F, Pontrandolfo P, Scozzi B. Logistics social responsibility: Standard adoption and practices in Italian companies. Inter J Production Economics. 2008;113(1):88-106.

38. Schaltegger S, Csutora, M. Carbon accounting for sustainability and management. Status quo and challenges. J Cleaner Production. 2012;36:1-16.

39. Branco MC, Rodrigues LL. Positioning stakeholder theory within the debate on corporate social responsibility. Electronic J Business Ethics \& Organization Studies. 2007;12(1):5-15.

40. Brennan NM, Merkl Davies DM. Rhetoric and argument in social and environmental reporting: the Dirty Laundry case. Accounting, Auditing \& Accountability J. 2014;27(4):602-633.

41. Kozlowski A, Searcy C, Bardecki M. Corporate sustainability reporting in the apparel industry: An analysis of indicators disclosed. Inter J Productivity \& Performance Management. 2015;64(3):377-397.

42. Johnsen TE, Miemczyk J, Howard M. A systematic literature review of sustainable purchasing and supply research: Theoretical perspectives and opportunities for IMP-based research. Industrial Marketing Management. 2016. p. 1-14.

43. Li Y, Zhao X, Shi D, et al. Governance of sustainable supply chains in the fast fashion industry. European Management J. 2014;32(5):823-836.

44. Karaosman H, Morales Alonso G, Brun A. From a Systematic Literature Review to a Classification Framework: Sustainability Integration in Fashion Operations. Sustainability. 2016;9(1):30.

45. D'Arpizio C, Levato F, Zito D, et al. Luxury Goods Worldwide Market Study. Bain \& Company, Milan, Italy; 2015. p. 1-36.

46. Brun A, Caniato F, Caridi M, et al. Logistics and supply chain management in luxury fashion retail: Empirical investigation of Italian firms. Inter J Production Economics. 2008;114(2):554-570. 
47. Karaosman H, Brun A. The myth of sustainability in fashion supply chains. In: Vecchi A, Buckley C, editors. Handbook of Research on Global Fashion Management and Merchandising. IGI Global. 2016. p. 481-509.

48. Parmigiani A, Klassen RD, Russo MV. Efficiency meets accountability: Performance implications of supply chain configuration, control, and capabilities. J Operations Management. 2011;29(3):212-223.

49. Eisenhardt KM, Martin JA. Dynamic capabilities: What are they? Strategic Management J. 2000;21(10-11):1105-1121.

50. Wu Z, Pagell M. Balancing priorities: Decision-making in sustainable supply chain management. $J$ Operations Management. 2011;29(6):577-590.

51. Kleindorfer P, Singhal K, Van Wassenhove L. Sustainable operations management. Production \& Operations Management. 2005;14(4):482-492.

52. Lo CKY, Yeung ACL, Cheng TCE. The impact of environmental management systems on financial performance in fashion and textiles industries. Inter J Production Economics. 2012;135(2):561-567.
53. Blome C, Paulraj A, Schuetz K. Supply chain collaboration and sustainability: a profile deviation analysis. Inter $J$ Operations \& Production Management. 2014;34(5):639-663.

54. King AA, Leonx MJ. Lean and green? An empirical examination of the relationship between lean production and environmental performance. Production \& Operations Management. 2009;10(3):244-256.

55. Porter M, Kramer M. Strategy and society: The link between competitive advantage and CSR. Harv Bus Rev. 2006;84(12):78-94.

56. Yin RK. Case Study Research: Design and Methods. Thousand Oaks. California: Sage Publications, 1994.

57. Yin RK. Case Study Research: Design and Methods. 4th ed. California: Sage Publications; 2009. p. 94-101. 